\title{
Anthocyanins abrogate glutamate-induced AMPK activation, oxidative stress, neuroinflammation, and neurodegeneration in postnatal rat brain
}

Shahid Ali Shah, Faiz UI Amin, Mehtab Khan, Muhammad Noman Abid, Shafiq Ur Rehman, Tae Hyun Kim, Min Woo Kim and Myeong Ok Kim*

\begin{abstract}
Background: Glutamate-induced excitotoxicity, oxidative damage, and neuroinflammation are believed to play an important role in the development of a number of CNS disorders. We recently reported that a high dose of glutamate could induce AMPK-mediated neurodegeneration in the postnatal day 7 (PND7) rat brain. Yet, the mechanism of glutamate-induced oxidative stress and neuroinflammation in the postnatal brain is not well understood. Here, we report for the first time the mechanism of glutamate-induced oxidative damage, neuroinflammation, and neuroprotection by polyphenolic anthocyanins in PND7.
\end{abstract}

Methods: PND7 rat brains, SH-SY5Y, and BV2 cells treated either alone with glutamate or in combination with anthocyanins and compound $C$ were examined with Western blot and immunofluorescence techniques. Additionally, reactive oxygen species (ROS) assay and other ELISA kit assays were employed to know the therapeutic efficacy of anthocyanins against glutamate.

Results: A single injection of glutamate to developing rats significantly increased brain glutamate levels, activated and phosphorylated AMPK induction, and inhibited nuclear factor-E2-related factor 2 (Nrf2) after 2, 3, and $4 \mathrm{~h}$ in a timedependent manner. In contrast, anthocyanin co-treatment significantly reduced glutamate-induced AMPK induction, ROS production, neuroinflammation, and neurodegeneration in the developing rat brain. Most importantly, anthocyanins increased glutathione (GSH and GSSG) levels and stimulated the endogenous antioxidant system, including Nrf2 and heme oxygenase-1 (HO-1), against glutamate-induced oxidative stress. Interestingly, blocking AMPK with compound C in young rats abolished glutamate-induced neurotoxicity. Similarly, all these experiments were replicated in SH-SY5Y cells by silencing AMPK with siRNA, which suggests that AMPK is the key mediator in glutamate-induced neurotoxicity.

Conclusions: Here, we report for the first time that anthocyanins can potentially decrease glutamate-induced neurotoxicity in young rats. Our work demonstrates that glutamate is toxic to the developing rat brain and that anthocyanins can minimize the severity of glutamate-induced neurotoxicity in an AMPK-dependent manner.

Keywords: Anthocyanins, Glutamate, AMPK, ROS, Neurotoxicity, Nrf2

\footnotetext{
* Correspondence: mokim@gsnu.ac.kr

Neuroscience Pioneer Research Center, Department of Biology and Applied

Life Science (BK21), College of Natural Sciences, Gyeongsang National

University, Jinju 660-701, Republic of Korea
}

(c) The Author(s). 2016 Open Access This article is distributed under the terms of the Creative Commons Attribution 4.0 International License (http://creativecommons.org/licenses/by/4.0/), which permits unrestricted use, distribution, and reproduction in any medium, provided you give appropriate credit to the original author(s) and the source, provide a link to the Creative Commons license, and indicate if changes were made. The Creative Commons Public Domain Dedication waiver (http://creativecommons.org/publicdomain/zero/1.0/) applies to the data made available in this article, unless otherwise stated. 


\section{Background}

The central nervous system (CNS) is comprised of several neurotransmitter receptors, with glutamate receptors being one of the major excitatory neurotransmitter receptors that have multiple functions, such as neuronal plasticity, outgrowth, and survival, as well as memory, learning, and behavior [1]. Conversely, glutamate release is under the control of various glutamate transporters as exposure to elevated levels is harmful to neurons. The overstimulation of postsynaptic glutamate receptors causes neuronal injury/death, which is termed as glutamate excitotoxicity as is believed to be involved in amyotrophic lateral sclerosis (ALS) and several other CNS disorders [2-4]. This glutamate excitotoxicity is believed to arise specifically from the entrance of a high rate of $\mathrm{Ca}^{2+}$ into the neurons as a result of overstimulated postsynaptic glutamate receptors [5]. The excess amount of intracellular $\mathrm{Ca}^{2+}$ levels can increase the burden of mitochondrial $\mathrm{Ca}^{2+}$, thereby inducing mitochondrial damage and reactive oxygen species (ROS) generation in the mitochondria [6-8]. Overproduction of ROS is thought to cause a diversity of diseases. There is a sophisticated antioxidant defense mechanism in cells that aides in coping with ROS levels under normal physiological conditions, but under certain conditions, such as excessive ROS and inflammation, excessive $\mathrm{Ca}^{2+}$ can cause cellular dysfunction and remodeling $[9,10]$.

NF-E2-related factor 2 (Nrf2) is a transcription factor that is bound to the antioxidant response element (ARE) and can induce the regulation of various antioxidant encoding genes, particularly heme oxygenase- 1 (HO-1) [11]. Previous reports have proven that the activation of Nrf2 in cells and tissues in response to oxidative stress protects against oxidative injury. Under normal conditions, Nrf2 is localized in the cytoplasm [12], while under oxidative stress conditions, it translocates into the nucleus and transactivates its target genes through ARE. Various protein kinases have been reported to be involved in the ARE-mediated gene Nrf2 activation in response to the oxidative stress signals including 5' AMP-activated protein kinase (AMPK) [13]. AMPK primarily functions as an energy sensor [14]. AMPK activation not only suppresses ATP-consuming metabolic pathways but also accelerates the energy-producing signaling pathways to offer cellular protection against any stress.

Natural polyphenolic compounds that are obtained from fruits and vegetables have received a great deal of interest during the last decade, due to their potential to inhibit oxidative stress, as reported in various studies [15]. Anthocyanins are a group of natural phenolic compounds that confer the different colors of plants and fruits. Evidence suggests that anthocyanins are strong natural antioxidants [16, 17]. Our research group has recently reported the anti-apoptotic, antioxidant, and anti-obesity effects of Korean black bean-derived anthocyanins in different experimental models [18-22].

In the current study, we extended our line of investigation to elucidate the exact mechanism of the neuroprotection of Korean black bean-derived anthocyanins against glutamate-induced excitotoxicity, oxidative stress, neuroinflammation, and neurodegeneration in the hippocampus of the developing rat brain and in SH-SY5Y and BV2 cells.

\section{Methods}

\section{Animals and drug treatment}

Sprague-Dawley (SD) rat pups (18-g average body weight) on postnatal day 7 ( $n=5$ rats/group) were randomly divided into the following eight groups (the treatment outlines are given in Additional file 1):

1. Control (C)

2. Glutamate for $2 \mathrm{~h}$ (Glu $2 \mathrm{~h}$ )

3. Glutamate for $3 \mathrm{~h}$ (Glu $3 \mathrm{~h}$ )

4. Glutamate for $4 \mathrm{~h}$ (Glu $4 \mathrm{~h}$ )

5. Glutamate for $4 \mathrm{~h}+$ anthocyanins (Glu $4 \mathrm{~h}+$ Anth)

6. Glutamate for $4 \mathrm{~h}+$ compound $\mathrm{C}(\mathrm{Glu} 4 \mathrm{~h}+\mathrm{CC})$

7. Glutamate for $4 \mathrm{~h}+$ compound $\mathrm{C}+$ anthocyanins (Glu $4 \mathrm{~h}+\mathrm{CC}+$ Anth)

8. Anthocyanins (Anth)

Glutamate $(10 \mathrm{mg} / \mathrm{kg})$, anthocyanins $(100 \mathrm{mg} / \mathrm{kg})$, and compound $C(10 \mathrm{mg} / \mathrm{kg})$ [23] in saline solution were intraperitoneally (i.p.) injected. Glutamate was administered for 2,3 , or $4 \mathrm{~h}$. The control animals received $0.9 \%$ saline solution, and all the rats were decapitated after 2, 3, or 4-12 h. All the experimental procedures were approved by local ethical committee for animals of the Department of Biology, Division of Applied Life Sciences, Gyeongsang National University South Korea.

\section{Cell culturing and drug treatment}

Murine BV2 microglia and human neuroblastoma SHSY5Y cells were maintained in $10 \%$ FBS- and $1 \%$ penicillin/streptomycin-supplemented DMEM (Dulbecco's modified Eagle's medium) medium in a humidified $5 \%$ $\mathrm{CO}_{2}$ incubator at $37{ }^{\circ} \mathrm{C}$. The cells were treated with glutamate $(30 \mathrm{mM})$, glutamate plus anthocyanins (30 $\mathrm{mM}+20 \mu \mathrm{g} / \mathrm{ml})$, glutamate plus AMPK siRNA $(30 \mathrm{mM}+200 \mathrm{nM})$, glutamate plus AMPK siRNA plus anthocyanins $(30 \mathrm{mM}+200 \mathrm{nM}+20 \mu \mathrm{g} / \mathrm{ml})$, glutamate plus compound $\mathrm{C}(30 \mathrm{mM}+20 \mu \mathrm{M})$, and glutamate plus compound $\mathrm{C}$ and anthocyanins $(30 \mathrm{mM}+20 \mu \mathrm{M}$ $+20 \mu \mathrm{g} / \mathrm{ml}$ ) for $3 \mathrm{~h}$. 


\section{AMPK gene silencing}

Small interfering RNA (siRNA) was purchased from Santa Cruz Biotechnology (sc-45312). Cultured SHSY5Y cells were transfected with $200 \mathrm{nM}$ siRNA using Lipofectamine 2000 reagent (Invitrogen) for 24 h [24], then the DMEM medium was replaced with glutamate and anthocyanins as indicated in the respective "Methods" section.

\section{Cell viability assay}

The MTT (3-(4,5-dimethylthiazol-2-yl)-2,5-diphenyltetrazolium bromide) assay was performed according to the manufacturer's instructions (Sigma) to assess the SH-SY5Y cell viability after treatment. The cells were cultured in 96-well plates at a density of $1 \times 10^{4}$ cells per well containing $100 \mu \mathrm{l}$ DMEM. When the cells were attached after $24 \mathrm{~h}$, the medium was refreshed with the indicated concentration of glutamate $(10,20$, and $30 \mathrm{mM})$ and anthocyanins $(10,20$, and $30 \mu \mathrm{g} / \mathrm{ml}$ ), while control cells received only DMEM medium. The cells were then incubated for an additional $3 \mathrm{~h}$. After being cultured for $3 \mathrm{~h}$, the cells were incubated with MTT solution for another $4 \mathrm{~h}$ at $37{ }^{\circ} \mathrm{C}$. Subsequently, the medium was replaced with DMSO in each well. Finally, the absorbance was measured at $570 \mathrm{~nm}$. All experiments were performed independently in triplicate.

\section{Western blot analysis}

Western blot analysis details were conducted as previously performed in our lab [25]. Briefly, the animals were euthanized after $4 \mathrm{~h}$ following treatment of glutamate with or without anthocyanins. Then, the brains were carefully (hippocampus) collected and placed on dry ice for freezing tissue. Similarly, after treatment, the SHSY5Y and BV2 cells were collected in PBS and centrifuged, and the supernatant was removed. The remaining pellet was dissolved in Pro Prep Protein Extraction Solution, according to the manufacturer's protocol (iNtRON Biotechnology) to make cell lysates. The brain homogenates and cell lysates were quantified with Bio-Rad protein assay solution. The homogenates $(20 \mu \mathrm{g}$ protein $)$ were fractionated by SDS-PAGE on 4-12 \% $\left(\right.$ Bolt $^{\text {ti }}$ Mini Gels, Life Technologies). After transfer, membranes were blocked in $5 \%$ skim milk (or BSA) and incubated overnight at $4{ }^{\circ} \mathrm{C}$ with primary antibody, and cross-reacting proteins were detected by ECL after reaction with horseradish peroxidase-conjugated secondary antibodies. The primary antibodies (1: 500 in Tris-buffered saline with Tween (TBST)) included rabbit-derived anti-COX2, anti-TNF $\alpha$, anti-p-AMPKTh ${ }^{172}$, anti-AMPK, anti-Nrf2, anti-caspase-3, anti-iNOS, anti-p-NF- $k \mathrm{~B}$, mouse-derived anti- $\beta$-actin, anti-GFAP, anti-heme oxygenase- 1 (HO- 1 ), and goat-derived anti-Iba-1 from Santa Cruz Biotechnology (Santa Cruz, CA, USA). After using membrane- derived secondary antibodies (1: 1000 in TBST), ECL (Amersham Pharmacia Biotech, Uppsala, Sweden) detection reagent was used for visualization according to the manufacturer's instructions. Densitometry analysis of the bands was performed using Sigma Gel software (SPSS, Chicago, IL, USA). Density values were calculated in arbitrary units (A.U.) relative to the untreated control.

\section{Tissue collection and sample preparation}

The animals were euthanized after $12 \mathrm{~h}$ of drug treatment to conduct morphological studies as we reported earlier [26]. Briefly, the brain tissues from all the treated groups after $12 \mathrm{~h}$ were subjected to transcardial perfusion with $4 \%$ ice-cold paraformaldehyde. After postfixing these brain tissues, $4 \%$ paraformaldehyde was transferred to $20 \%$ sucrose. The tissues were frozen in OCT (TissueTek O.C.T. Compound Medium, Sakura Finetek USA, Inc., Torrance, CA, USA), sectioned into 14-16- $\mu \mathrm{m}$ sections in the coronal plane with a CM 3050S cryostat (Leica, Wetzlar, Germany). The sections were thawmounted on Probe-On positively charged slides (Thermo Fisher Scientific Inc., Waltham, MA, USA).

\section{Fluoro-Jade B staining}

Fluoro-Jade B staining was performed as reported earlier [27]. Chamber slides were air-dried overnight. The slides were kept in a solution of $80 \%$ ethanol and $1 \%$ sodium hydroxide then in $70 \%$ alcohol for 5 and $2 \mathrm{~min}$, respectively, followed by immersion in distilled water for $2 \mathrm{~min}$. The slides were placed for $10 \mathrm{~min}$ in $0.06 \%$ potassium permanganate solution. The slides were then rinsed with distilled water and immersed in a solution containing $0.1 \%$ acetic acid and $0.01 \%$ Fluoro-Jade B for 20 min. After rinsing with distilled water and applying DAPI, the slides were dried, and glass cover slips were mounted on slides with mounting medium. Images were captured using an FITC filter on a confocal laser scanning microscope (FV 1000, Olympus, Japan).

\section{Immunofluorescence}

Immunofluorescence stainings were performed as we previously reported [19]. Shortly, the slides were washed with $1 \times$ PBS and incubated with proteinase $\mathrm{K}$ solution at room temperature. After blocking in normal goat/rabbit serum, primary antibodies (1: 100 in PBS, mentioned in the "Western blotting" section) were applied overnight at $4{ }^{\circ} \mathrm{C}$. Fluorescence-based (FITC and TRITC from Santa Cruz Biotechnology) secondary antibodies (in PBS) were applied at room temperature. DAPI was used to stain the nucleus. The slides were mounted with glass coverslips, and the images were taken using a confocal microscope (FluoView FV 1000; Olympus, Tokyo, Japan). 


\section{TUNEL staining}

To determine apoptotic cell death, TUNEL (terminal deoxynucleotidyl transferase (TdT)-mediated dUTP nick-end labeling) staining was performed according to the manufacturer's recommendations. An in situ cell death detection kit was purchased from Roche (Cat. No. 11684809910).

\section{Oxidative stress (ROS) detection in vivo and in vitro}

The ROS quantification assay in the brain homogenates of all treated groups was conducted as reported earlier in the literature and by our research group $[28,29]$ with slight modification. Briefly, the brain homogenates from the respective groups were diluted 1:20 times with Locke's buffer (ice-cold) to get $5 \mathrm{mg}$ tissue/ml concentration. Then, the reaction mixture $(1 \mathrm{ml})$ having Locke's buffer of $\mathrm{pH}$ 7.4, $0.2 \mathrm{ml}$ brain homogenate, and $10 \mathrm{ml}$ of DCFH-DA (5 mM) was incubated for $15 \mathrm{~min}$ at room temperature to allow the DCFH-DA to be incorporated into any membrane-bound vesicles and the diacetate group cleaved by esterases. After $30 \mathrm{~min}$ of further incubation, the conversion of DCFH-DA to the fluorescent product DCF was measured using a spectrofluorometer with excitation at $484 \mathrm{~nm}$ and emission at $530 \mathrm{~nm}$. ROS formation was quantified from a DCF-standard curve and data are expressed as pmol DCF formed $/ \mathrm{min} / \mathrm{mg}$ protein. Similarly, an in vitro ROS assay was performed with slight modification as previously described [26]. Briefly; SH-SY5Y cells were sub-cultured in 96-well plates in $200 \mu \mathrm{l}$ DMEM that was supplemented with $10 \% \mathrm{FBS}$ and $1 \%$ penicillin/streptomycin in every well. The cells were incubated for $24 \mathrm{~h}$ at $37{ }^{\circ} \mathrm{C}$ in a humidified incubator having $5 \% \mathrm{CO}_{2}$. The next day, the media was replaced by fresh media that contained Glu (30 $\mathrm{mM})$, Glu plus anthocyanins $(30 \mathrm{mM}+20 \mu \mathrm{g} / \mathrm{ml})$, Glu plus compound $\mathrm{C}(30 \mathrm{mM}+20 \mu \mathrm{M})$, or Glu plus compound $\mathrm{C}$ and anthocyanins $(30 \mathrm{mM}+20 \mu \mathrm{M}+$ $20 \mu \mathrm{g} / \mathrm{ml})$ for an additional $30 \mathrm{~min}$. DCFDA $\left(2^{\prime}, 7^{\prime}-\right.$ dichlorofluorescin diacetate) $600 \mu \mathrm{M}$ dissolved in DMSO/PBS was added to each well and incubated for $30 \mathrm{~min}$. The plates were then read in ApoTox-Glo ${ }^{\text {rx }}$ (Promega) at $488 / 530 \mathrm{~nm}$.

\section{Glutamate assay}

Glutamate assay kit (Cat. \# KA1670) from Abnova (Taipei, Taiwan) was used to quantify glutamate in hippocampal brain tissue homogenates according to the manufacturer's instruction.

\section{Enzyme assays}

The hippocampal rat brain homogenates and SH-SY5Y cell lysates of the experimental groups were evaluated using ELISA assays for total NF- ${ }_{k} \mathrm{Bp} 65$ (Life Technologies, Catalog \#KHO0371) and Cyclex AMPK (Enzo Life
Sciences), as per the manufacturer's recommended protocols.

\section{COX2 assay}

An ELISA assay for COX2 (R\&D Systems, Inc. 614 McKinley Place NE Minneapolis, MN 55413, USA) was performed. BV2 and SH-SY5Y cells were sub-cultured in 96-well plates, and treatment was performed in different groups, as described earlier, and then fixed with $4 \%$ paraformaldehyde, as per the manufacturer's recommendations.

\section{GSH assays}

The levels of total GSH and GSH/GSSG ratio were determined by using glutathione assay kit obtained from BioVision (BioVision Incorporated155 S. Milpitas Boulevard, Milpitas, CA 95035, USA), Fluorometric Assay Kit (Catalog \#K264-100), according to the manufacturer's instructions.

\section{Statistical analysis}

A computer-based Sigma Gel System (SPSS Inc., Chicago, IL) and the ImageJ program were used to analyze the density and integral optical density (IOD) of scanned X-ray films of Western blot and immunofluorescence images. Density values were expressed as the mean \pm SEM. All data are presented as the mean \pm SEM. A one-way ANOVA followed by Student's $t$ test (nonparametric Mann-Whitney and Wilcoxon tests) were used to determine the statistical significance $(P<0.05)$ of the obtained data.

\section{Results}

Exogenous glutamate induced multiple neurotoxic effects in the developing rat brain in a time-dependent manner

The brain glutamate level was analyzed with a glutamate assay kit method in developing brain homogenates after exogenous glutamate administration. Our results (Fig. 1a) indicated that exogenous glutamate produced significant up-regulation of brain glutamate in the hippocampus of young rats after 2,3 , and $4 \mathrm{~h}$ (where $4 \mathrm{~h}$ was the most significant increase in glutamate level) following its administration in a time-dependent manner. Similarly, glutamate also induced the activities of AMPK and NF- ${ }_{k}$ Bp65 in the same manner within 2 to $4 \mathrm{~h}$, as assessed with the help of a respective ELISA assay kit method (Fig. 1b, c). We then examined the protein expression level of AMPAR, phosphorylated $\mathrm{AMPK}^{\mathrm{Th} 172}$ (p-AMPK), Nrf2, and phosphorylated nuclear factor kappa (p-NF- ${ }_{k} \mathrm{~B}$ ) in the hippocampal brain homogenates of the developing brain in a timedependent manner. The results (Fig. 1d) indicate that exogenous glutamate administered to the developing rats significantly increased the expression level of 


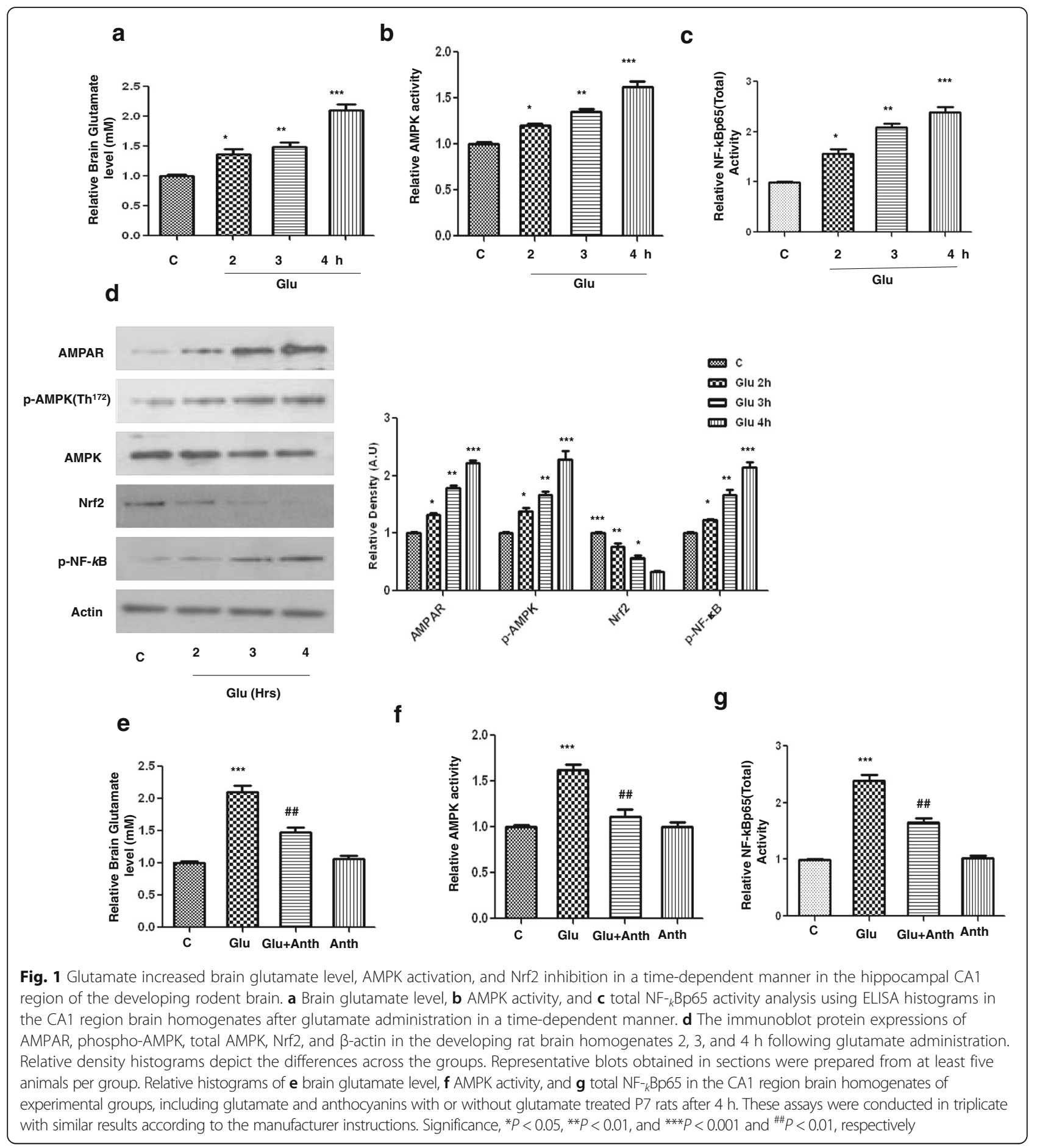

AMPARs, p-AMPK, and p-NF- ${ }_{k} \mathrm{~B}$ after 2,3 , and $4 \mathrm{~h}$ in the hippocampus (whereas after $5 \mathrm{~h}$, glutamate level and its toxic effects began to decline and that data is not shown here). Similarly, this glutamate also caused the inhibition of hippocampal Nrf2 proteins in a timedependent manner (Fig. 1d).

\section{Anthocyanins are beneficial against glutamate-induced neurotoxicity in the developing brain}

We then evaluated the therapeutic efficacy of anthocyanins against glutamate-induced neurotoxicity in the developing rat brain. As shown above, it was observed that exogenous glutamate could cause a maximal up- 
regulation of hippocampal brain glutamate levels as well as AMPK and NF- ${ }_{k} \mathrm{Bp} 65$ activities $4 \mathrm{~h}$ after its administration. For this reason, we co-treated rat pups with anthocyanins along with glutamate. Anthocyanin treatment significantly reduced brain hippocampal glutamate levels as well as AMPK and $\mathrm{NF}_{-} \mathrm{B}$ activities against exogenously injected glutamate (Fig. 1e-g). Similarly, Western blot results revealed that anthocyanin administration also significantly down-regulated glutamate-induced
AMPA receptor expression and p-AMPK activation in the developing rat brain (Fig. 2a). Immunofluorescence investigation of p-AMPK also supported our Western blot results that indicated that anthocyanins could reduce glutamate-induced AMPK activation in the hippocampal CA1 region (Fig. 2b). Additionally, the exogenously administered glutamate also increased the intracellular calcium abundance by upregulating the expression level of CaMKII protein, which was accompanied

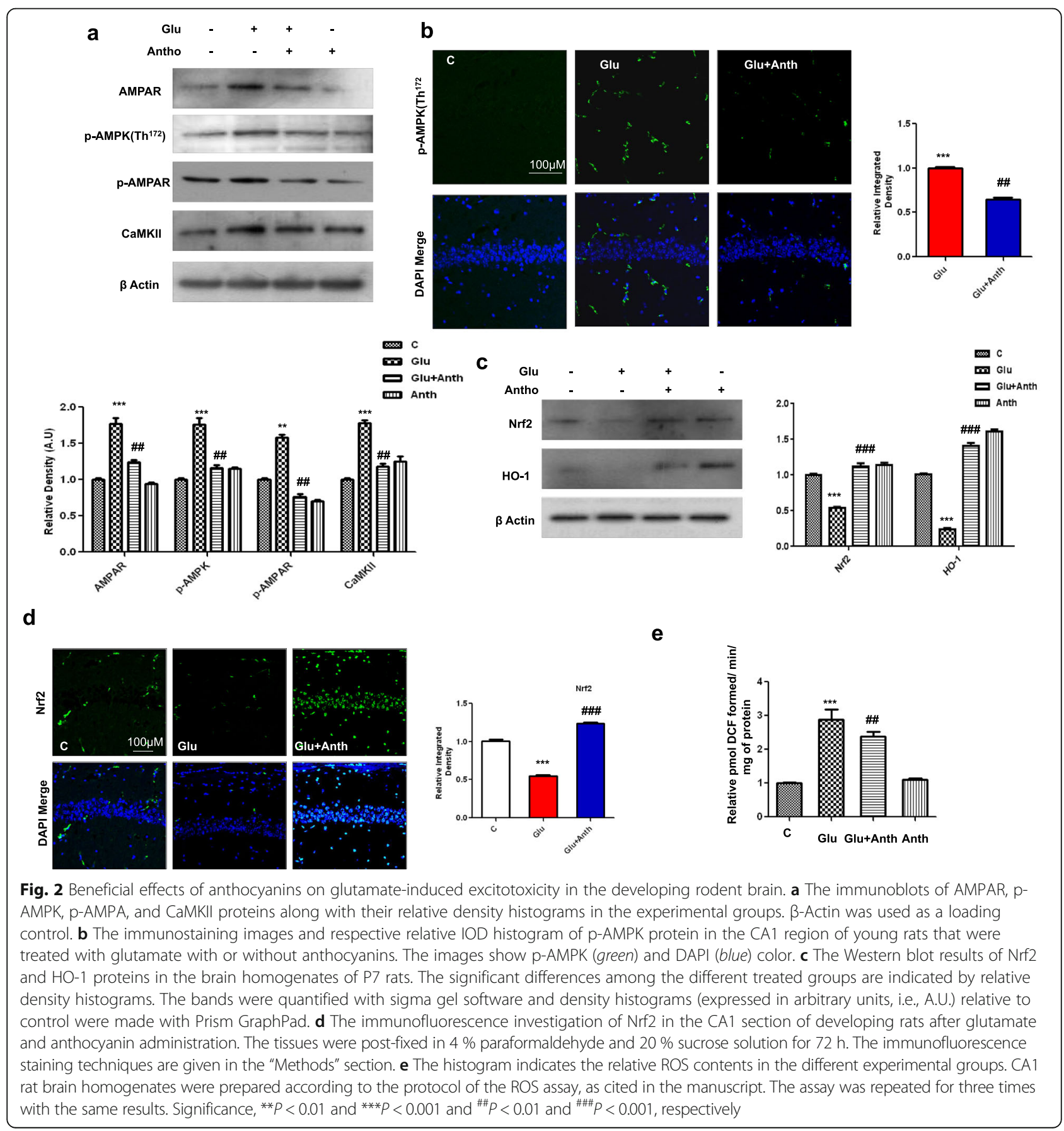


by AMPA receptor phosphorylation at $\mathrm{Ser}^{845}$ (i.e., pAMPA Ser ${ }^{845}$ ); however, the rat pups that received anthocyanins as a co-treatment significantly inhibited the glutamate-induced up-regulation of CaMKII and pAMPA Ser ${ }^{845}$ protein expression, as shown in Fig. 2a.

\section{Anthocyanins increased cellular glutathione levels and activated the Nrf2/HO-1 signaling pathway against} glutamate-induced oxidative stress in the developing brain To examine the antioxidant effect of anthocyanins, we first analyzed glutathione (GSH and GSSG) levels accompanied by the quantification of the expression of Nrf2 protein and its downstream signaling gene heme oxygenase-1 (HO-1) with immunoblotting. Our results show that glutamate treatment after $4 \mathrm{~h}$ significantly reduced cellular GSH content and GSH/GSSG ratio compared with the saline-treated control in the developing rat brain (Additional file 1: Fig. S1). Anthocyanins treatment significantly increased cellular GSH content and GSH/GSSG ratio against glutamate (Additional file 1: Fig. S1). Similarly, we have already shown that exogenously administered glutamate can significantly suppress Nrf2 after $4 \mathrm{~h}$ (Fig. 1d). For this reason, the rat pups that received anthocyanins with or without glutamate were euthanized after $4 \mathrm{~h}$ and their brain homogenates were subjected to Western blotting and a ROS assay. The Western blot results revealed that anthocyanin treatment significantly increased the expression of Nrf2 and HO-1 proteins in the developing brain. Additionally, the immunofluorescence examination of Nrf2 protein in brain tissue agreed with our immunoblot results and showed that anthocyanin treatment increased the expression of Nrf2 (in the nucleus, as shown Additional file 1) in the hippocampal CA1 region of the developing rat brain (Fig. 2c, d, the high magnification expanded image is given in Additional file 1). Glutamate has been reported for its ability to produce ROS. For this reason, the ROS assay was conducted with the brain homogenates of the experimental groups. The assay results indicated that anthocyanin treatment significantly inhibited glutamate-induced ROS production in the developing rat brain (Fig. 2e).

\section{Anthocyanins attenuated glutamate-induced neuroinflammation and neurodegeneration}

The extent of neuroinflammation that was induced by glutamate was assessed with immunofluorescence, Western blot, and ELISA assays. A single episode of glutamate injection caused significant induction of glial cell activation, including both astrocytes (GFAP) and microglia (Iba-1) (Fig. 3a, b), which was accompanied by upregulated proinflammatory $\mathrm{p}-\mathrm{NF}_{-k} \mathrm{~B}$ and its downstream signaling molecules, such as cyclooxygenase-2 (COX-2), tumor necrosis factor- $\alpha$ (TNF- $\alpha$ ), and caspase-3 protein expressions in the hippocampal CA1 region of the developing rat brain (Fig. 3c). Anthocyanin supplementation significantly attenuated not only glutamate-induced glial cells activation but also markedly inhibited p-NF- ${ }_{k} \mathrm{~B}, \mathrm{COX}-2$, and caspase- 3 protein expression, as assessed with immunofluorescence and Western blotting methods. The activity histogram of NF- ${ }_{k} \mathrm{Bp} 65$ (total), which was examined with the ELISA methods, is also in agreement with the immunoblot results that anthocyanins can inhibit p-NF- ${ }_{k} \mathrm{~B}$ activity in the developing brain (Fig. 3d). Additionally, glutamate-induced neurodegeneration in the immature rodent brain was assessed with TUNEL staining. The results revealed that glutamate was able to induce significant DNA fragmentation in the hippocampal CA1 region of the developing rodent brain. In contrast, anthocyanin treatment significantly decreased glutamate-induced DNA fragmentation in the CA1 region of the P7 rodent brain (Fig. 3e).

\section{Glutamate-induced neurotoxicity is AMPK dependent in the developing rat brain}

To determine whether glutamate-induced neurotoxicity is AMPK dependent, we injected compound $\mathrm{C}$, an inhibitor of AMPK, along with glutamate or without anthocyanins into immature rats. Interestingly, compound $\mathrm{C}$ administration significantly reduced glutamate-induced AMPK activation, as shown in Fig. 4a, b. These results show that compound $\mathrm{C}$ after $4 \mathrm{~h}$ blocked AMPK protein expression (Fig. 4a) as well as activity (Fig. 4b), as indicated by Western blot and ELISA assay, respectively. Accordingly, the ROS assay that was conducted also supports the notion that glutamate-induced ROS can activate AMPK, as compound $\mathrm{C}$ has no effect on the ability of either glutamate-induced oxidative stress or anthocyanins to reduce ROS in the developing brain (Fig. 4c). We measured Nrf2 and HO-1 proteins levels using Western blot analysis. The immunoblot quantification revealed that compound $\mathrm{C}$ significantly blocked the ability of glutamate to suppress $\mathrm{Nrf} 2$ and $\mathrm{HO}-1$ in the developing rat brain (Fig. 4d). Similarly, compound $\mathrm{C}$ also blocked glutamate from significantly activating $\mathrm{p}-\mathrm{NF}_{-} \mathrm{B}$ (both its activity and expression), COX2, and caspase- 3 proteins in the hippocampus of the young rat brain (Fig. 4d, e). Interestingly, compound $\mathrm{C}$ treatment affected the ability of anthocyanins to up-regulate $\mathrm{Nrf2}, \mathrm{HO}-1, \mathrm{p}-\mathrm{NF}_{-} \mathrm{B}, \mathrm{COX} 2$, and caspase-3 proteins (Fig. 4a, d, e). This suggests that in the postnatal rat brain, glutamate produces its neurotoxicity by activating AMPK.

\section{Anthocyanins enhanced cell viability and decreased glutamate-induced neurodegeneration in vitro}

The MTT assay was conducted to measure the cell viability of SH-SY5Y cells after treatment with different concentrations of glutamate and anthocyanins. The 
a
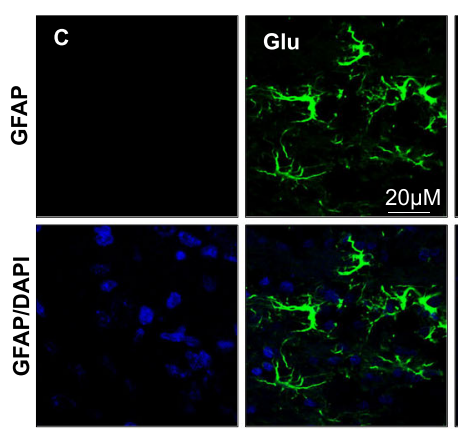

GFAP

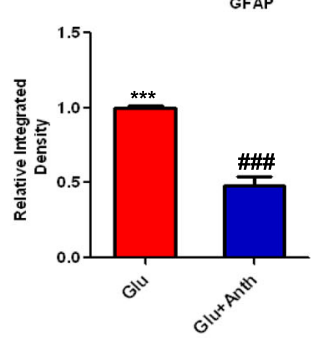

C
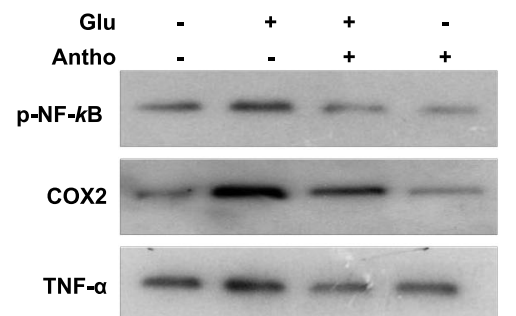

Caspase-3

$\beta$ Actin

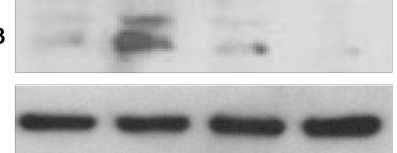

b
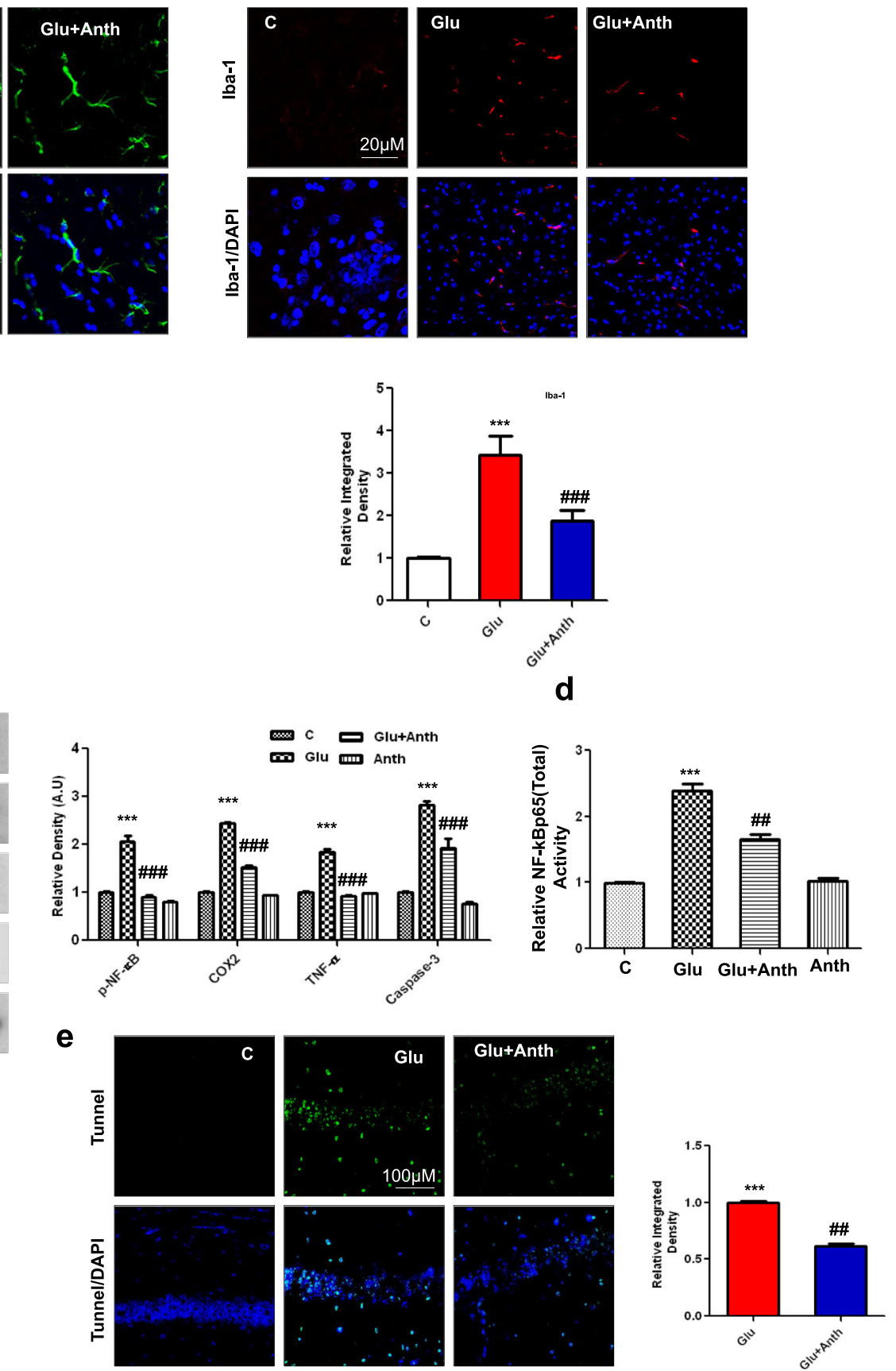

Fig. 3 Anthocyanins reduced glutamate-induced glial cell activation, neuroinflammation, and DNA damage in hippocampal CA1 region of the developing rat brain. Given are representative immunofluorescence images along with relative IOD histograms of a astrocytes (GFAP)-positive cells and $\mathbf{b}$ microglia (Iba-1)-positive cells in the CA1 region of experimental groups. Images represent immunostaining performed with tissue sections prepared from at least five rats in each group. Panels representing hippocampal CA1 region immunostained with GFAP (green), Iba-1 (red) counterstained with DAPI (blue) of young rat brain. c The immunoblot represents proinflammatory markers, including p-NF- $\mathrm{B}, \mathrm{COX} 2$ and TNF-a proteins, which are accompanied by their relative density histograms. $\mathbf{d}$ The ELISA histogram of NF- ${ }_{k} \mathrm{Bp} 65$ (total) in the brain homogenates of treated animals. The assay was repeated three times according to the manufacturer's instruction. e The extent of DNA damage in the CA1 region by glutamate was analyzed by conducting TUNEL assay. To quantify DNA damage, ImageJ and Prism GraphPad programs were used. The values represent the mean \pm SEM for the indicated proteins ( $n=5$ animals per group). Significance, ${ }^{* * *} P<0.001$ and ${ }^{\# \#} P<0.01$ and ${ }^{\# \# \#} P<0.001$, respectively 

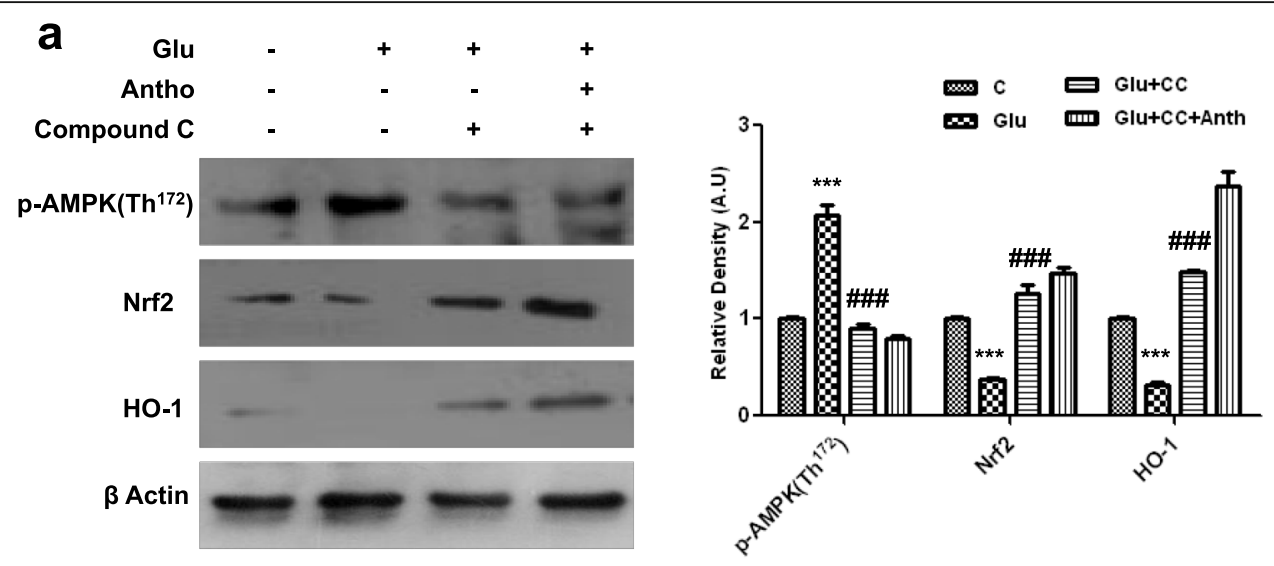

b
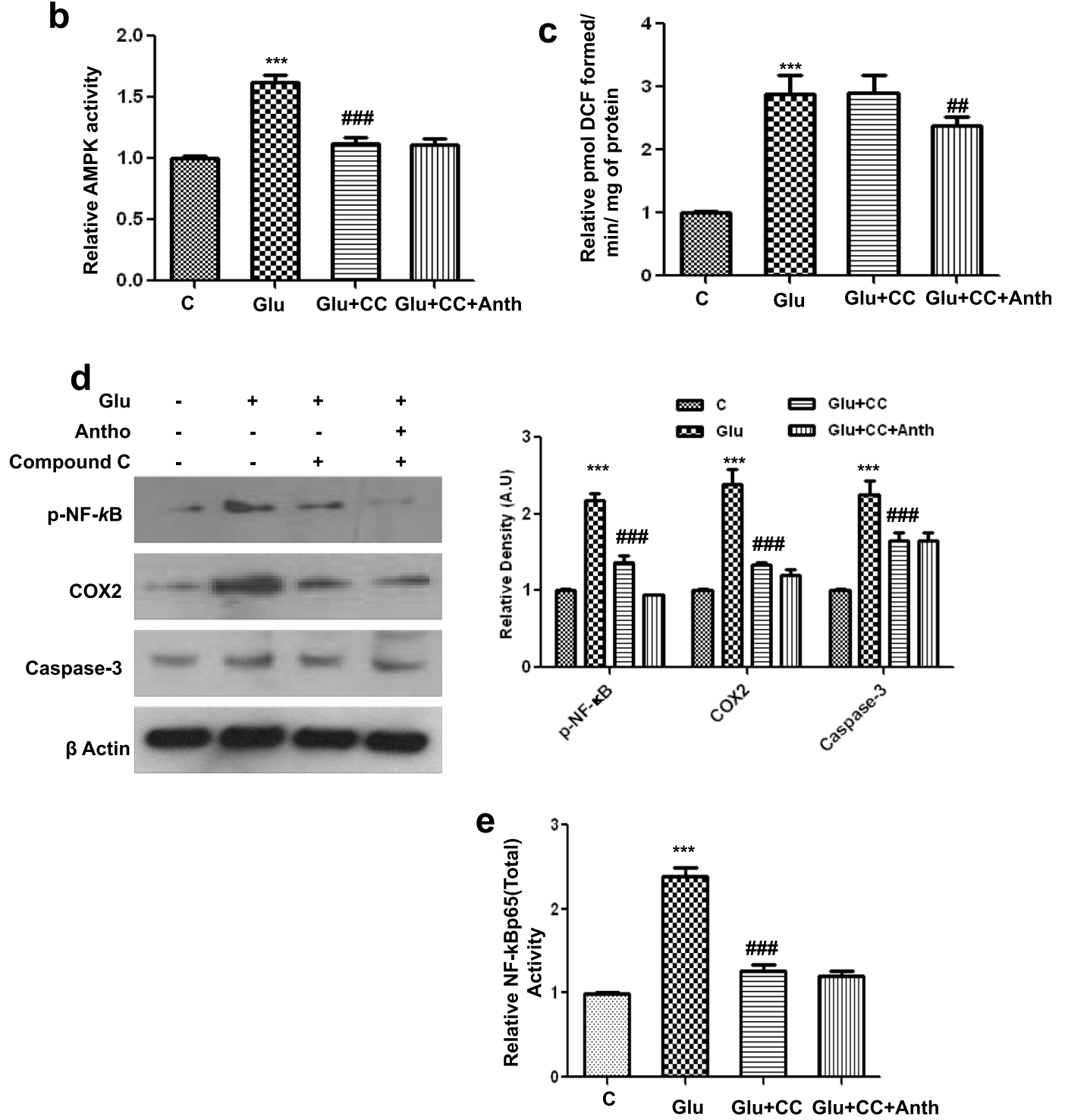

Fig. 4 (See legend on next page.) 


\section{(See figure on previous page.)}

Fig. 4 Glutamate-induced neurotoxicity in the developing rodent brain is AMPK dependent. a The expression level of p-AMPK, Nrf2, and HO-1 proteins in the P7 rat brain homogenates that were treated with glutamate or glutamate with or without compound $\mathrm{C}$ and anthocyanins for $4 \mathrm{~h}$. Their densities were measured with the help of Sigma Gel software. Their respective relative density histograms were made with Prism GraphPad. The membranes were redeveloped for $\beta$-actin and used as a loading control. b, c The histograms of AMPK activity and ROS assay were conducted with brain homogenates of the abovementioned experimental animal groups. The assays were performed in triplicate with the same results. $\mathbf{d}$ The Western blot analysis of p-NF- $\mathrm{B}, \mathrm{COX} 2$, and caspase-3 proteins in the hippocampus of postnatal day 7 rat brain following treatment with glutamate, glutamate and compound C, or glutamate, compound C, and anthocyanins. The relative integrated density for the abovementioned proteins are depicted in the histograms. The density values are expressed in arbitrary units as the mean \pm SEM for the indicated proteins ( $n=5$ animals per group). Details are provided in the "Methods" section. e The activity histogram of NF-kB65 (total) in the brain homogenates of treated animal's measured with ELISA kit method. Significance; ${ }^{* * *} P<0.001$ and ${ }^{\# \#} P<0.001$, respectively

results show that anthocyanins in three different concentrations (i.e., 10,20 , and $30 \mu \mathrm{g} / \mathrm{ml}$ ) were non-toxic to cells (Fig. 5a), in contrast to that of glutamate in three concentrations (i.e., 10, 20, and $30 \mathrm{mM}$ ), which significantly reduced SH-SY5Y cell viability (Fig. 5b). Similarly, all three different concentrations of anthocyanins significantly increased SH-SY5Y cell viability against glutamate (30 mM), as shown in Fig. 5c. Additionally, the extent of glutamate-induced neuronal loss was measured through Fluoro-Jade B (FJB) staining in SH-SY5Y cells. The FJB results indicated that glutamate $(30 \mathrm{mM})$ significantly induced neuronal apoptosis in SH-SY5Y cells, as shown in Fig. 5d. Similarly, these images also revealed that anthocyanins $(20 \mu \mathrm{g} / \mathrm{ml})$ reduced the extent of neuronal apoptosis in vitro (Fig. 5d).

\section{Glutamate-induced neurotoxicity in vitro is AMPK dependent}

The mechanism of action of glutamate in vitro was confirmed by conducting experiments with SH-SY5Y and BV2 cells. We first silenced AMPK with its siRNA and then analyzed the expression levels of different proteins. The results showed that the anthocyanin treatment significantly reduced p-AMPK immunoreactivity (Fig. 5e) and AMPK activity (Fig. 5f) against glutamate in $\mathrm{SH}$ SY5Y cells. Similarly, anthocyanin treatment also reduced glutamate-increased p-AMPK protein expression, as shown in Fig. 5g. Additionally, anthocyanins enhanced Nrf2 and HO-1 expression, which are antagonistic towards the effects of excessive glutamate, in vitro (Fig. 5g). The expressions levels of Nrf2 were measured both with immunoblotting and immunofluorescence methods (Fig. 5g, h). AMPK was silenced with its siRNA, which not only decreased p-AMPK activity but also reduced its expression (Fig. 5f, g). Interestingly, the effect of anthocyanins on the expressions level of pAMPK, Nrf2, and HO-1 was also observed following siRNA-mediated AMPK silencing (Fig. 5f). Similarly, the ROS assay that was conducted revealed that anthocyanins significantly inhibited glutamate-induced ROS production in cells. Again, compound $\mathrm{C}$ was observed to have no effect on ROS generation, thereby supporting our in vivo results that this ROS is independent of AMPK in vitro as well (Fig. 5i).

We then measured the expression level of $\mathrm{p}-\mathrm{NF}_{-} \mathrm{B}$, COX2 and caspase- 3 after treating with glutamate and anthocyanins with or without AMPK siRNA-treated SHSY5Y cells. Again, anthocyanins significantly reduced the expression level of $\mathrm{p}-\mathrm{NF}-{ }_{k} \mathrm{~B}, \mathrm{COX} 2$ and caspase-3; however, AMPK knock-down completely blocked the ability of glutamate to up-regulate the abovementioned proinflammatory and apoptotic marker in SH-SY5Y cells (Fig. 6a). The silencing of AMPK also affected the inhibitory potential of anthocyanins. Similarly, the activities of $\mathrm{NF}_{-k} \mathrm{~B}$ and $\mathrm{COX} 2$, as measured by ELISA kit methods, also supported the notion that glutamateinduced $\mathrm{NF}_{-k} \mathrm{~B}$ and $\mathrm{COX} 2$ activity up-regulation was AMPK dependent (Fig. 6b, c).

We also used BV2 cells to examine the beneficial effects of anthocyanins against glutamate-induced cytotoxicity. The double immunofluorescence results indicated that anthocyanins reduced the expression levels of $\mathrm{p}$ AMPK and p-NF- ${ }_{k} \mathrm{~B}$ against glutamate in BV2 cells (Fig. 6d). Similarly, anthocyanin treatment enhanced Nrf2 immunoreactivity in the nucleus of BV2 cells (Fig. 6e). Additionally, we analyzed the activity of COX2 by blocking AMPK with compound $\mathrm{C}$ in vitro and measuring activity via an ELISA kit. The results showed that anthocyanin treatment decreased glutamate-induced COX2 activity (Fig. 6f). Compound $\mathrm{C}$ treatment diminished the ability of glutamate to induce an increase in COX2 activity and reduced anthocyanins ability to inhibit COX2 activity in BV2 cells, which indicates that this process is dependent upon AMPK (Fig. 6f). All these events in the current study are highlighted in detail in the Fig. 7.

\section{Discussion}

The current study demonstrates several important findings (as shown in detail in Fig. 7). First, it reports that exogenously administered glutamate in the developing rat can increase brain glutamate levels as well as activate and phosphorylate AMPK and $\mathrm{NF}_{k} \mathrm{~B}$, which is accompanied by Nrf2 protein inhibition. These toxic effects 


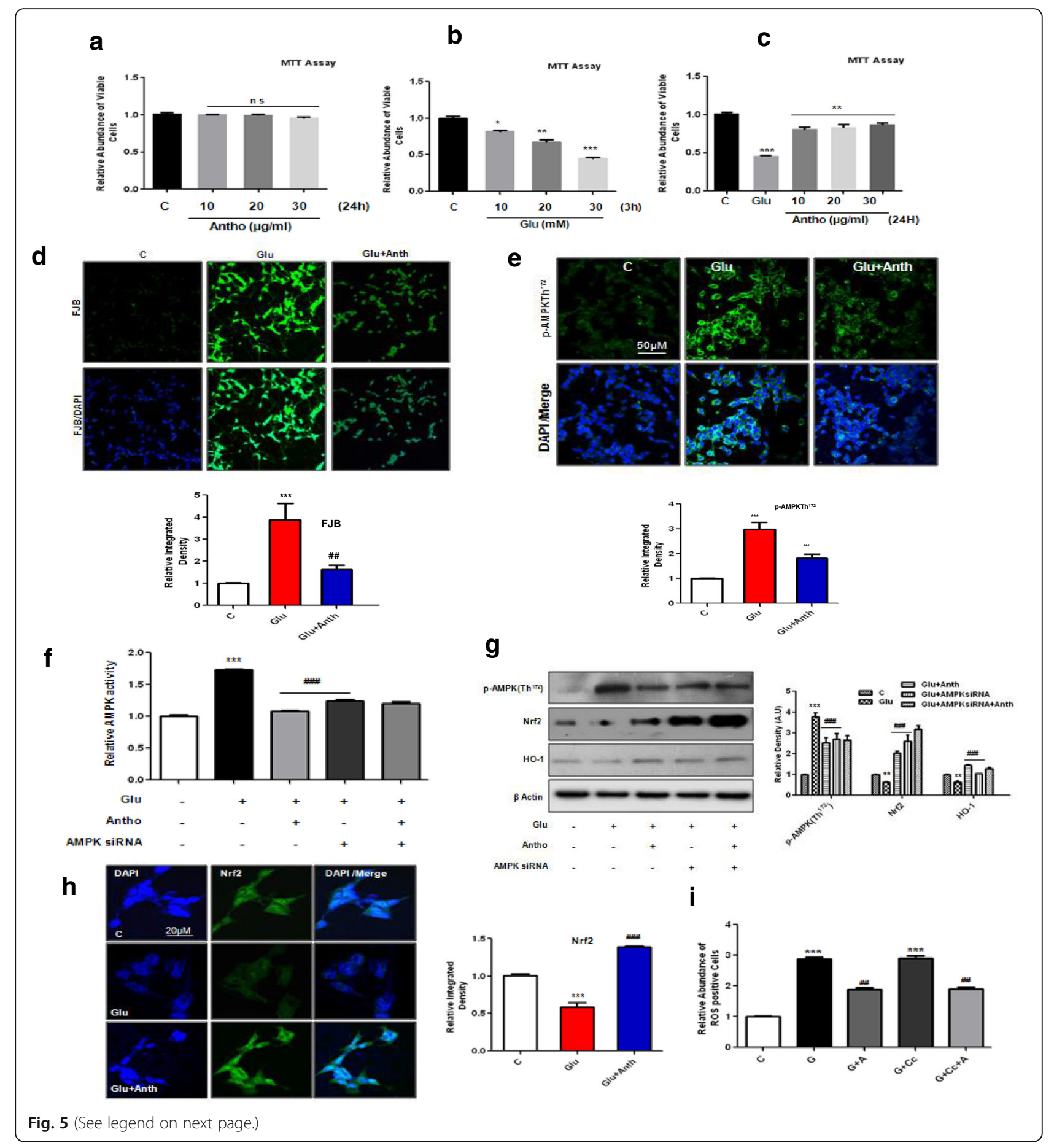




\begin{abstract}
(See figure on previous page.)
Fig. 5 The beneficial effects of anthocyanins against glutamate-induced toxicity in SH-SY5Y cells. a-c The cell viability histograms of SH-SY5Y cells, as indicated by the MTT assay. a The cells were incubated with three different (indicated) concentrations of anthocyanins for $24 \mathrm{~h}$. $\mathbf{b}$ The cell viability histogram of SH-SY5Y cells that were treated with the indicated concentrations of glutamate for $3 \mathrm{~h}$. c The cell viability histogram after pretreating cells $(12 \mathrm{~h}$ ) with three concentrations of anthocyanins and glutamate $(30 \mathrm{mM})$ for additional $3 \mathrm{~h}$. All details are provided in the "Methods" section. $\mathbf{d}$ The immunofluorescence images and respective relative IOD histogram of FJB (green)-positive and DAPI (blue) SH-SY5Y cells. Cells were grown in four-well chamber slides and then treated with the mentioned ("Methods" section) concentrations of glutamate and anthocyanins. The FJB staining was repeated in triplicate. e The immunostained images of p-AMPK (green) protein counterstained with DAPI (blue) in the SH-SY5Y cells. The panels represent different treating groups such as untreated control, glutamate, or glutamate and anthocyanins. $\mathbf{f}$ The histogram of relative AMPK activity assay conducted with cell lysate experimental treating groups having siRNA of AMPK. $\mathbf{g}$ The Western blot analysis of p-AMPK, Nrf2, and HO-1 protein expressions and their relative density histograms after treating cells with glutamate and glutamate and anthocyanins and in the presence or absence of AMPK siRNA. $\mathbf{h}$ The immunostaining images and respective relative IOD histograms of Nrf2 protein in SH-SY5Y cells. i The ROS assay histogram after treating SH-SY5Y cells with glutamate or glutamate and anthocyanins with or without compound C. The groups and other experimental details are provided in the "Methods" section. Significance, ${ }^{*} P<0.05,{ }^{* *} P<0.01$, ${ }^{* *} P<0.001$ and ${ }^{\# \#} P<0.01$ and ${ }^{\# \# \#} P<0.001$, respectively
\end{abstract}

that were induced by glutamate were observed following 2,3 , and $4 \mathrm{~h}$ of its administration, as measured and quantified by Western blot and ELISA assays. Those results indicate that glutamate can induce a maximal toxic effect after $4 \mathrm{~h}$ when compared to 2 and $3 \mathrm{~h}$. Second, this study provides evidence that after $4 \mathrm{~h}$, anthocyanins can reduce brain glutamate levels, AMPK activation, ROS production, and inflammation. Third, anthocyanins increased glutathione levels and stimulated $\mathrm{Nrf} 2 / \mathrm{HO}-1$ signaling, which has an important role in cellular defense against oxidants and toxic chemicals. Finally, we reported that blocking AMPK either with compound $\mathrm{C}$ or with siRNA not only negatively regulates glutamateinduced AMPK activation and inflammation but also can abolish the neuroprotective abilities of anthocyanins in young rats as well as in SH-SY5Y cells.

AMPK and oxidative stress have long been associated with neurodegenerative diseases. Oxidative stress disrupts mitochondrial respiration and damages mitochondria, which ultimately induce apoptotic cell death and degeneration [30]. Mitochondria, a major regulator of apoptosis, have an important role in controlling cell life and death [31]. Current findings indicate that anthocyanins decrease glutamate-induced ROS and energy reduction, thereby protecting against oxidative stress.

Here, for the first time, we found that AMPK signaling mediates a crucial role in the antioxidant activity of anthocyanins against glutamate-induced oxidative stress. This beneficial effect of anthocyanins, both in young rats and in cells, is associated with up-regulation of glutathione (both GSH levels and GSSG ratio) and the stimulation of Nrf2/HO-1 as an important antioxidant-signaling pathway. Our findings demonstrated that anthocyanins both inhibited glutamate-upregulated proinflammatory and neuroapoptotic markers as well as suppressed endogenous antioxidant molecules via activated AMPK reduction. Recently, anthocyanins have been shown to exert AMPK-mediated neuroprotection against kainic acid-induced excitotoxicity in cells [22]. Anthocyanins are comprised of various flavonoids that have been reported to have beneficial effects against oxidative stress, inflammation, and neurodegeneration [32-34]. These beneficial effects of anthocyanins are due to their antioxidative characteristics, as demonstrated by several researchers in their reports $[16,17]$. Similarly, numerous studies have indicated that cyanidin-3-O-glucoside (C3G), one of the active components of anthocyanins, is a potent neuroprotective agent against cerebral ischemia and $\beta$-amyloid-induced mitochondrial damage $[35,36]$ and can block the release of apoptosis-inducing factor (AIF) in focal cerebral ischemia [37]. The blueberryenriched diet has been shown to reduce kainic acidinduced oxidative stress and excitotoxicity mediated memory impairment [38].

Oxidative stress is one of the earliest pathological changes in neurodegenerative diseases such as Alzheimer's disease (AD). The hippocampus and cortex sections of the brain are vulnerable to oxidative stress and are associated with the development of cognitive impairment as a feature of sporadic AD. Similarly, another risk factor for AD is aging, in which the endogenous system is unable to scavenge free radicals and ultimately produces oxidative stress in the brain [39]. Additionally, the brain has a relatively weak antioxidant defense system compared to other organs of the body and so the activation of the endogenous antioxidant system is particularly vital for those tissues. In this regard, the stimulation of Nrf2-ARE signaling pathways in the brain has been considered as one of the major pharmaceutical strategies for the treatment and prevention of neurodegenerative disease and brain aging. Nrf2 is believed to be involved in regulating phase II antioxidant responses, which induce the activation of several free radical scavengers and beneficial enzymes. HO- 1 is one of the important genes in the brain and is activated by Nrf2, as demonstrated by intensive studies that have a crucial role in providing shelter to neurons against cell death. Accordingly, numerous reports have described that Nrf2 activation $[40,41]$ induces an increase in HO-1 in response to 


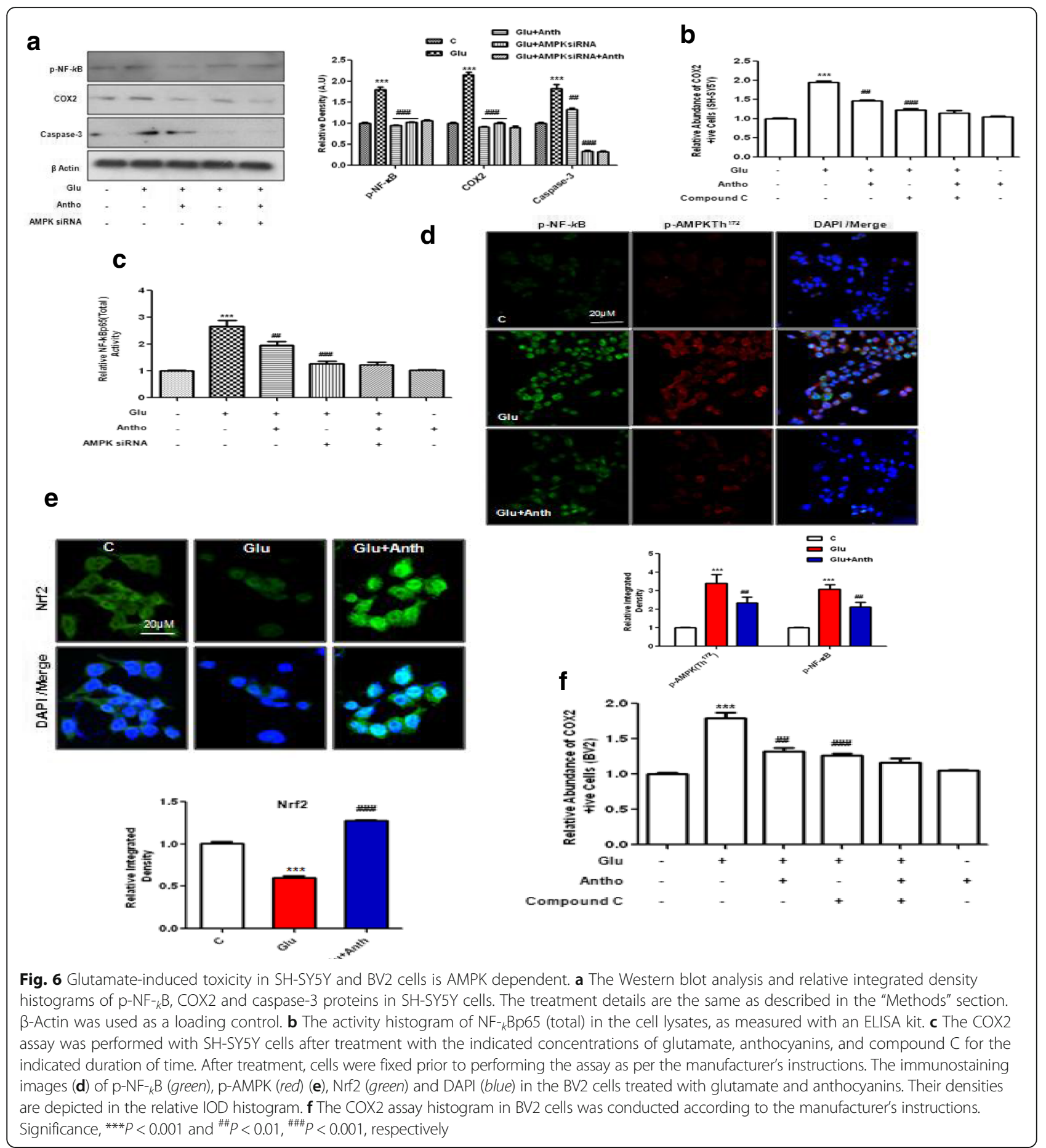

several neurodegenerative disorders [42]. Many studies have shown that HO-1 activation is an important response to the threat of oxidative stress to neurons as it can rescue neurons from oxidative stress and cell death [43, 44]. HO1 has been strongly linked to reduced inflammation [45]. Similarly, HO-1 knockout mice have been shown to develop inflammatory disease and are sensitive to experimental sepsis [46], while the pharmacological activation of
HO- 1 has been found to be beneficial in the inflammation animal model [47]. Excessive glutamate that is triggered by oxidative stress or ROS accumulation induces neuronal apoptosis and cell death. This process is similar in nature to numerous neurodegenerative diseases and some pathological conditions, such as ischemia and trauma $[3,48,49]$. The literature has shown that glutamate can induce Nrf2 and HO-1 suppression, which is followed by the induction 


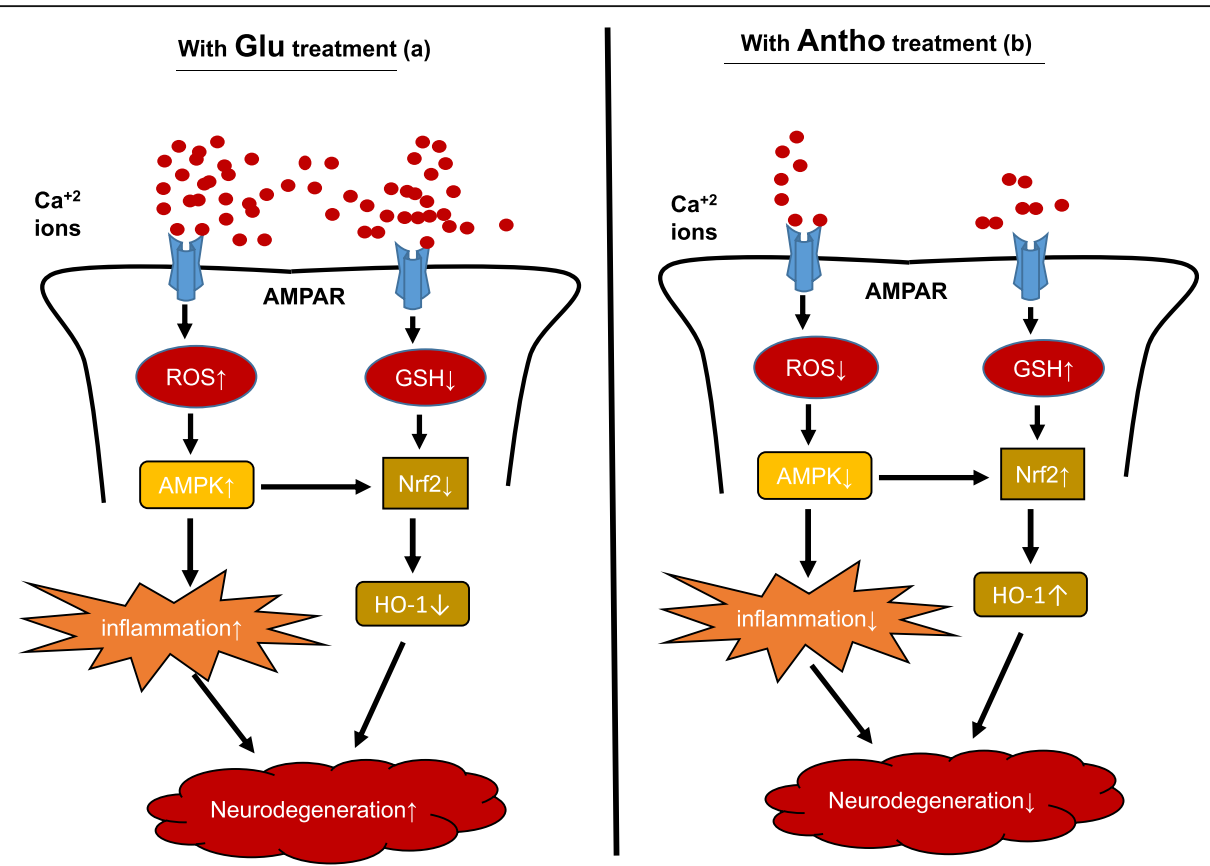

Fig. 7 The signaling pathway of anthocyanins neuroprotection against the glutamate-induced neurotoxicity. This scheme depicts the number of various events taking place after the glutamate (a) and anthocyanins (b) treatments. It is evident from the flow sheet that anthocyanins treatment completely inhibited glutamate-induced neurodegeneration in the developing rats

of inflammation and neurodegeneration in the postnatal brain as well as in cells. In the present study, we have demonstrated that a single dose of exogenously provided glutamate caused the induction of neuroinflammation and neurodegeneration in the postnatal rat brain. Additionally, glutamate treatment in SH-SY5Y and BV2 cells also induced the activation of proinflammatory and proapoptotic markers, such as $\mathrm{NF}_{k} \mathrm{~B}$ and caspase- 3 expression. As per our results, these toxic effects of glutamate are AMPK dependent because our findings indicate that either compound $\mathrm{C}$ or siRNA-mediated silencing of AMPK can diminish the toxic effects of glutamate treatment both in vivo and in vitro.

Although some additional work is necessary to elucidate the mechanisms that are involved in this current network, the findings from this study have identified a major role of AMPK activation by anthocyanins in the attenuation of oxidative stress through the activation of $\mathrm{Nrf} 2 / \mathrm{HO}-1$ signaling. Furthermore, our study suggests that anthocyanins might be a pharmacological therapeutic agent for use in combination with other potential drugs in the treatment of various neurodegenerative diseases.

\section{Conclusions}

Our data demonstrate that glutamate could induce its neurotoxicity within 2-3 h in AMPK-dependent manner in the developing rat's brain. Similarly, we report for the first time that the ability of anthocyanins to reverse glutamate-suppressed $\mathrm{Nrf} 2 / \mathrm{HO}-1$ is AMPK dependent in young rats. This study demonstrates that anthocyanin is a highly potent agent in vivo and in vitro against glutamate-induced oxidative stress and neurodegeneration as it have attractive drug-like properties.

\section{Additional file}

Additional file 1: Figure S1. Anthocyanin upregulated glutathione levels (GSH and GSH/GSSG ratio) against glutamate in the developing rat brain. The histograms show (a) the levels of total Glutathione (GSH) and (b) the ratio of GSH/GSSG in the brain homogenates of rat pups $4 \mathrm{~h}$ after glutamate and anthocyanin treatment. All the procedures were followed as provided by the manufacturer. These assays were performed in triplicate with the same results. Significance, ${ }^{* *} P<0.001$ and ${ }^{\# \#} P<0.001$, respectively. Figure S2d. (PDF $189 \mathrm{~kb}$ )

\section{Abbreviations}

ALS: Amyotrophic lateral sclerosis; AMPK: 5 ' adenosine monophosphateactivated protein kinase; CNS: Central nervous system; DCFH-DA: Dichlorodihydro-fluorescein diacetate; DMEM: Dulbecco's modified Eagle's medium; DMSO: Dimethyl sulfoxide; FBS: Fetal bovine serum; FJB: Fluoro-Jade B; HO1: Heme oxygenase-1; MTT: 3-(4,5-dimethylthiazol-2-yl)-2,5diphenyltetrazolium bromide; Nrf2: Nuclear factor-E2-related factor 2; ROS: Reactive oxygen species; SD: Sprague-Dawley; SDS-PAGE: Sodium dodecyl sulfate polyacrylamide gel electrophoresis; TUNEL: Terminal deoxynucleotidyl transferase (TdT)-mediated dUTP nick-end labeling 


\section{Funding}

This research was supported by the Brain Research Program through the National Research Foundation of Korea funded by the Ministry of Science ICT \& Future Planning (2016M3C7A1904391). This funding body is involved in the design, collection, analysis, and interpretation of the data and the writing of the manuscript.

\section{Availability of data and materials}

All the authors hereby state that the data presented here in any form is freely available for the scientists to use without breaching participant confidentiality.

\section{Authors' contributions}

SAS designed this work and performed most of the experiments and analyses and wrote the manuscript. FUA and MK conducted the in vivo studies and also contributed in vitro. MNAand SUR performed the in vitro experiments. KTH assisted in most of the experiments and analyses, while MWK helped in the revision process. MOK is the corresponding author and holds all the responsibilities regarding this manuscript. All authors read and approved the final manuscript.

\section{Competing interests}

The authors declare that they have no competing interests.

\section{Consent for publication}

Not applicable (NA).

\section{Ethics approval}

All the experimental procedures were approved by local ethical committee for animals of the Department of Biology, Division of Applied Life Sciences, Gyeongsang National University South Korea.

\section{Received: 6 June 2016 Accepted: 26 October 2016}

\section{Published online: 08 November 2016}

\section{References}

1. Akbarian S, Sucher NJ, Bradley D, Tafazzoli A, Trinh D, Hetrick WP, Potkin SG, Sandman CA, Bunney WEJ, Jones EG. Selective alterations in gene expression for NMDA receptor subunits in prefrontal cortex of schizophrenics. J of Neurosci. 1996;51:19-30

2. Bosch LVD, Damme PV, Bogaert E, Robberecht W. The role of excitotoxicity in the pathogenesis of amyotrophic lateral sclerosis. Biochim Biophys Acta. 2006;1762:1068-82.

3. Coyle JT, Puttfarcken P. Oxidative stress, glutamate, and neurodegenerative disorders. Science. 1993;262:689-95.

4. Lipton SA, Rosenberg PA. Excitatory amino acids as a final common pathway for neurologic disorders. N Engl J Med. 1994;330:613-22.

5. Choi DW. Glutamate neurotoxicity and diseases of the nervous system. Neuron. 1988; 1:623-34.

6. Carriedo SG, Sensi SL, Yin HZ, Weiss JH. AMPA exposures induce mitochondrial $\mathrm{Ca}(2+)$ overload and ROS generation in spinal motor neurons in vitro. J Neurosci. 2000;20:240-50.

7. Carriedo SG, Yin $\mathrm{HZ}$, Sensi SL, Weiss JH. Rapid $\mathrm{Ca}^{2+}$ entry through $\mathrm{Ca}^{2}$ ${ }^{+}$-permeable AMPA/kainate channels triggers marked intracellular $\mathrm{Ca}^{2+}$ rises and consequent oxygen radical production. J Neurosci. 1998;18:7727-38.

8. Ankarcrona M, Dypbukt JM, Bonfoco E, Zhivotovsky B, Orrenius S, Lipton SA, Nicotera P. Glutamate induced neuronal death: a succession of necrosis or apoptosis depending on mitochondrial function. Neuron. 1995;15:961-73.

9. Finkel T. Signal transduction by reactive oxygen species. J Cell Biol. 2011; 194:7-15

10. Valko M, Leibfritz D, Moncol J, Cronin MT, Mazur M, Telser J. Free radicals and antioxidants in normal physiological functions and human disease. Int J Biochem Cell Biol. 2007;39:44-84.

11. Kweon MH, Adhami VM, Lee JS, Mukhtar H. Constitutive overexpression of Nrf2-dependent heme oxygenase-1 in A549 cells contributes to resistance to apoptosis induced by epigallocatechin 3-gallate. J Biol Chem. 2006;281: 33761-72.

12. Venugopal R, Jaiswal AK. Nrf1 and Nrf2 positively and c-Fos and Fra negatively regulate the human antioxidant response element-mediated expression of $\mathrm{NAD}(\mathrm{P}) \mathrm{H}$ : quinone oxidoreductase1 gene. Proc Natl Acad Sci U S A. 1996;93:14960-5.
13. Liu XM, Peyton KJ, Shebib AR, Wang H, Korthuis RJ, Durante W. Activation of AMPK stimulates heme oxygenase-1 gene expression and human endothelial cell survival. Am J Physiol Heart Circ Physiol. 2011;300:84-93.

14. Hardie DG, Carling D, Carlson M. The AMP-activated/SNF1 protein kinase subfamily: metabolic sensors of the eukaryotic cell? Annu Rev Biochem. 1998:67:821-55.

15. Pandey KB, Rizvi SI. Plant polyphenols as dietary antioxidants in human health and disease. Oxid Med and Cell Longevity. 2009;2:270-8.

16. Prior RL. Fruits and vegetables in the prevention of cellular oxidative damage. Am J Clin Nutr. 2003;78:570-8.

17. Bagchi D, Sen CK, Bagchi M, Atalay M. Anti-angiogenic, antioxidant, and anti-carcinogenic properties of a novel anthocyanin-rich berry extract formula. Biogeosciences. 2004;69:75-80.

18. Shah SA, Ullah I, Lee HY, Kim MO. Anthocyanins protect against ethanolinduced neuronal apoptosis via GABAB1 receptors intracellular signaling in prenatal rat hippocampal neurons. Mol Neurobiol. 2013;48:257-69.

19. Shah SA, Yoon GH, Kim MO. Protection of the developing brain with anthocyanins against ethanol-induced oxidative stress and neurodegeneration. Mol Neurobiol. 2015;51:1278-91.

20. Badshah $\mathrm{H}$, Kim TH, Kim MO. Protective effects of anthocyanins against amyloid beta-induced neurotoxicity in vivo and in vitro. Neurochem Internat. 2015;80:51-9.

21. Badshah H, Ullah I, Kim SE, Kim T, Lee HY, Kim MO. Anthocyanins attenuate body weight gain via modulating neuropeptide $Y$ and GABAB1 receptor in rats hypothalamus. Neuropeptides. 2013;47:347-53.

22. Ullah I, Park HY, Kim MO. Anthocyanins protect against kainic acid-induced excitotoxicity and apoptosis via ROS-activated AMPK pathway in hippocampal neurons. CNS Neuro \& Thera. 2014;20:327-38.

23. Kim E, Miller I, Aja S, Landree LE, Pinn M, McFadden J, Kuhajda FP, Moran TH, Ronnett GV. C75, a fatty acid synthase inhibitor, reduces food intake via hypothalamic AMP-activated protein kinase. J Bio Chem. 2004:279:19970-6.

24. Shah SA, Yoon GH, Chung SS, Abid MN, Kim TH, Lee HY, Kim MO. Novel osmotin inhibits SREBP2 via the AdipoR1/AMPK/SIRT1 pathway to improve Alzheimer's disease neuropathological deficits. Mol Psychiatry. 2016. doi:10.1038/mp.2016.23.

25. Shah SA, Yoon GH, Kim H, Kim MO. Vitamin C neuroprotection against dose-dependent glutamate-induced neurodegeneration in the postnatal brain. Neurochem Res. 2015;40:875-84.

26. Shah $S A$, Hae YL, Ray AB, Dae JY, Myeong OK. Novel osmotin attenuates glutamate-induced synaptic dysfunction and neurodegeneration via the JNK/PI3K/Akt pathway in postnatal rat brain. Cell Death Dis. 2014;5:1-10.

27. Shah SA, Yoon GH, Ahmad A, Ullah F, Amin FU, Kim MO. Nanoscale-alumina induces oxidative stress and accelerates amyloid beta $(A \beta)$ production in ICR female mice. Nanoscale. 2015;7:15225-37.

28. Shinomol GK, Muralidhara. Differential induction of oxidative impairments in brain regions of male mice following subchronic consumption of Khesari dhal (Lathyrus sativus) and detoxified Khesari dhal. Neurotoxicology. 2007; 28:798-806.

29. Shah SA, Khan M, Jo MH, Jo MG, Amin FU, Kim MO. Melatonin stimulates the SIRT1/Nrf2 signaling pathway counteracting lipopolysaccharide (LPS)induced oxidative stress to rescue postnatal rat brain. CNS Neurosci Ther. 2016:2016:1-12

30. Onyango IG, Khan SM. Oxidative stress, mitochondrial dysfunction, and stress signaling in Alzheimer's disease. Curr Alzheimer Res. 2006:3:339-49.

31. lijima T. Mitochondrial membrane potential and ischemic neuronal death. Neurosci Res. 2006:55:234-43.

32. Shih PH, Yeh CT, Yen GC. Anthocyanins induce the activation of phase 11 enzymes through the antioxidant response element pathway against oxidative stress-induced apoptosis. J Agric Food Chem. 2007:55:9427-35.

33. Karlsen A, Retterstøl L, Laake P, Paur I, Bøhn SK, Sandvik L, Blomhoff R. Anthocyanins inhibit nuclear factor-kF activation in monocytes and reduce plasma concentrations of pro-inflammatory mediators in healthy adults. J Nutr. 2007:137:1951-4.

34. Joseph JA, Arendash G, Gordon M, Diamond D, Shukitt-Hale B, Morgan D, Denisova NA. Blueberry supplementation enhances signaling and prevents behavioural deficits in an Alzheimer's disease model. Nutr Neurosci. 2005:6:153-62.

35. Kang TH, Hur JY, Kim HB, Ryu JH, Kim SY. Neuroprotective effects of the cyanidin-3-O-beta-D-glucopyranoside isolated from mulberry fruit against cerebral ischemia. Neurosci Lett. 2006;391:122-6. 
36. Ye J, Meng X, Yan C, Wang C. Effect of purple sweet potato anthocyanins on $\beta$-amyloid-mediated PC-12 cells death by inhibition of oxidative stress. Neurochem Res. 2010;35:357-65.

37. Kang TH, Hur JY, Kim HB, Ryu JH, Kim SY. Neuroprotective effect of cyanidin-3-o-glucoside anthocyanin in mice with cerebral ischemia. Neurosci Lett. 2011;500:157-61.

38. Duffy KB, Spangler EL, Devan BD, Guo Z, Bowker JL, Janas AM, Hagepanos A, Minor RK, DeCabo R, Mouton PR, Shukitt-Hale B, Joseph JA, Ingram DK. A blueberry-enriched diet provides cellular protection against oxidative stress and reduces a kainate-induced learning impairment in rats. Neurobiol Aging. 2008;29:1680-9.

39. Katzman R, Saitoh T. Advances in Alzheimer's disease. FASEB J. 1991;5:278-86.

40. Wu Q, Zhang XS, Wang HD, Zhang X, Yu Q, Li W, Zhou ML, Wang XL. Astaxanthin activates nuclear factor erythroid-related factor 2 and the antioxidant responsive element (Nrf2-ARE) pathway in the brain after subarachnoid hemorrhage in rats and attenuates early brain injury. Mar Drugs. 2014;12:6125-41.

41. Wu W, Wang X, Xiang Q, Meng X, Peng Y, Du N, Liu Z, Sun Q, Wang C, Liu $X$. Astaxanthin alleviates brain aging in rats by attenuating oxidative stress and increasing BDNF levels. Food Funct. 2014;5:158-66.

42. Vries HED, Witte M, Hondius D, Rozemuller AJ, Drukarch B, Hoozemans J, Van HJ. Nrf2-induced antioxidant protection: a promising target to counteract ROS-mediated damage in neurodegenerative disease? Free Radic Biol Med. 2008;45:1375-83.

43. Chen K, Gunter K, Maines MD. Neurons overexpressing heme oxygenase-1 resist oxidative stress-mediated cell death. J Neurochem. 2000;75:304-12.

44. Le WD, Xie WJ, Appel SH. Protective role of heme oxygenase-1 in oxidative stress-induced neuronal injury. J Neurosci Res. 1999;56:652-8.

45. Willis D, Moore AR, Frederick R, Willoughby DA. Heme oxygenase: a novel target for the modulation of the inflammatory response. Nat Med. 1996;2: 87-90.

46. Poss KD, Tonegawa S. Reduced stress defense in heme oxygenase 1deficient cells. Proc Natl Acad Sci U S A. 1997;94:10925-30.

47. Paine A, Eiz-Vesper B, Blasczyk R, Immenschuh S. Signaling to heme oxygenase-1 and its anti-inflammatory therapeutic potential. Biochem Pharmacol. 2010;80:1895-903.

48. Satoh T, Lipton SA. Redox regulation of neuronal survival mediated by electrophilic compounds. Trends Neurosci. 2007;30:37-45.

49. Satoh T, Enokido Y, Kubo K, Yamada M, Hatanaka H. Oxygen toxicity induces apoptosis in neuronal cells. Cell Mol Neurobiol. 1998;18:649-66.

\section{Submit your next manuscript to BioMed Central and we will help you at every step:}

- We accept pre-submission inquiries

- Our selector tool helps you to find the most relevant journal

- We provide round the clock customer support

- Convenient online submission

- Thorough peer review

- Inclusion in PubMed and all major indexing services

- Maximum visibility for your research

Submit your manuscript at www.biomedcentral.com/submit

) Biomed Central 